\title{
BMJ Global Health Bi-directional drones to strengthen healthcare provision: experiences and lessons from Madagascar, Malawi and Senegal
}

\author{
Astrid M Knoblauch, ${ }^{1,2,3}$ Sara de la Rosa, ${ }^{4}$ Judith Sherman, ${ }^{5}$ Carla Blauvelt, ${ }^{6}$ \\ Charles Matemba, ${ }^{6}$ Luciana Maxim, ${ }^{6}$ Olivier D Defawe, ${ }^{7}$ Abdoulaye Gueye, ${ }^{8}$ \\ Joanie Robertson, ${ }^{9}$ Jesse McKinney, ${ }^{3}$ Joe Brew, ${ }^{3}$ Enrique Paz, ${ }^{10}$ Peter M Small, ${ }^{3}$ \\ Marcel Tanner, ${ }^{2}$ Niaina Rakotosamimanana, ${ }^{1}$ Simon Grandjean Lapierre ${ }^{1,3,11}$
}

To cite: Knoblauch AM, de la Rosa S, Sherman J, et al. Bi-directional drones to strengthen healthcare provision: experiences and lessons from Madagascar, Malawi and Senegal. BMJ Global Health 2019;4:e001541. doi:10.1136/ bmjgh-2019-001541

Handling editor Seye Abimbola

- Additional material is published online only. To view please visit the journal online (http://dx.doi.org/10.1136/ bmjgh-2019-001541).

Received 28 February 2019 Revised 11 May 2019 Accepted 18 May 2019

\section{Check for updates}

\section{Author(s) (or their} employer(s)) 2019. Re-use permitted under CC BY-NC. No commercial re-use. See rights and permissions. Published by BMJ.

For numbered affiliations see end of article.

Correspondence to Dr Astrid M Knoblauch; astrid.knoblauch@swisstph.ch

\section{ABSTRACT}

Drones are increasingly being used globally for the support of healthcare programmes. Madagascar, Malawi and Senegal are among a group of early adopters piloting the use of bi-directional transport drones for health systems in sub-Saharan Africa. This article presents the experiences as well as the strengths, weaknesses, opportunities and threats (SWOT analysis) of these country projects. Methods for addressing regulatory, feasibility, acceptability, and monitoring and evaluation issues are presented to guide future implementations. Main recommendations for governments, implementers, drone providers and funders include (1) developing more reliable technologies, (2) thorough vetting of drone providers' capabilities during the selection process, (3) using and strengthening local capacity, (4) building in-country markets and businesses to maintain drone operations locally, (5) coordinating efforts among all stakeholders under government leadership, (6) implementing and identifying funding for long-term projects beyond pilots, and (7) evaluating impacts via standardised indicators. Sharing experiences and evidence from ongoing projects is needed to advance the use of drones for healthcare.

\section{INTRODUCTION}

Conventional health system strengthening approaches to enhance coverage of quality healthcare, such as capacity building, increased availability of commodities, improved infrastructure and adequate health financing, develop gradually. ${ }^{1}$ They will, in the short to medium term, have a limited effect on the health outcomes of hard-to-reach populations in remote areas of sub-Saharan Africa. New technologies have the potential to accelerate access to healthcare, commodities and data for beneficiaries, providers and policy-makers.

Unmanned aerial vehicles, or drones, are one example of technology that can have a multitude of public health applications including supply chain support (eg, transport
Summary box

Bi-directional transport drone technology is currently being explored and advanced in order to make it fit for real-world applications.

- First-hand experiences from pioneer projects with regards to regulations, stakeholder collaboration, feasibility, data collection and local acceptability provide foundational building blocks for other drone initiatives.

- Continued, longer-term investments and implementation are required to soundly assess the technology's impact.

- Sustainable integration of drones into health systems needs in-country capacities, markets and businesses to locally own and operate a drone-supported system.

of medications, vaccines, biological samples), emergency response (eg, transport of blood and plasma), disease prevention (eg, sterile mosquito release for vector control), deployment of networks for data harvesting in unconnected areas, and health research. ${ }^{2-9}$ In order to meet different needs, drones are available in various sizes, payload capacities, flight ranges, energy sources, propulsion systems, take-off/ recovery methods, cargo delivery configurations, automation levels and costs. 5

In 2014, for the first time, Médecins Sans Frontières demonstrated the potential of drones in healthcare by transporting sputum samples for tuberculosis (TB) diagnosis in Papua New Guinea. ${ }^{1011}$ Since then, drone-based healthcare projects have emerged worldwide for a wide array of use cases. This emergence is especially visible in sub-Saharan Africa. The most prominent example is the drone project initiated in 2016 by the Government of Rwanda for transportation of sachets of blood 
to peripheral health centres. ${ }^{12}$ This project has mastered one-way air-drop delivery and is the only fully operational project in sub-Saharan Africa as of February 2019. However, there are a number of pilot and proof-of-concept projects in other countries exploring bi-directional transport, that is, the ability to land in a remote health facility or a village and return.

In this relatively new field of bi-directional drone delivery, literature is scarce and mostly restricted to theoretical documentation, roadmaps, market landscape and use-case analyses. ${ }^{13-17}$ Due to the early stage of implementation and limited small-scale pilot projects, little real-world experience and primary data related to drone technology performance, operations, health impact, cost or acceptability are available to date. ${ }^{15}{ }^{18-23}$ Lessons learnt from sub-Saharan African pioneer drone projects represent the best available information from which to build on for future implementation.

In this article, we describe the regulatory, technical and operational aspects of the existing projects in Madagascar, Malawi and Senegal. The authors directly involved in the conceptualisation and implementation of the projects performed a SWOT analysis (strengths, weaknesses, opportunities and threats). Finally, we draw conclusions from common and differing experiences and lessons learnt from across the countries and provide guidance for governments, implementers, drone providers and funders for future healthcare drone projects in the African region and beyond.

\section{THE CASE OF MADAGASCAR}

Between 2016 and 2018, the 'DrOTS: Drones Observed Therapy System in Remote Madagascar' project was a proof-of-concept with a strong research component implemented by Stony Brook University (New York, USA) and the Pasteur Institute of Madagascar. The project combined a bundle of technologies (including drones, digital adherence monitors, cough counters and educational videos) in an innovative approach to forwardly deploy healthcare in remote settings. ${ }^{24}$ Drone technology was explored as a way of removing logistical barriers to quality TB care by flying sputum samples and medication for diagnosis and treatment between a centralised, well-equipped laboratory and remote villages in one district (table 1 and online supplementary file 1 ).$^{25}$ The technology requirement was a drone with a high degree of autonomy (ie, no manual piloting) that did not require a runway, launcher or other heavy infrastructure and that could perform bi-directional transport of goods for a $120 \mathrm{~km}$ flight range with a payload of up to 1 $\mathrm{kg}$. The project experienced three major obstacles: (1) the lack of drone-specific flight regulations led to delayed flight permit approval and required frequent renewals thereof; (2) the necessity of switching the drone technology early in the implementation phase due to the provider's inability to deliver functional drones; (3) the subsequent unavailability of a technology solution designed for the specific use case in real-world conditions of remote Madagascar (table 2). Consequently, a significant amount of resources were allocated to administrative procedures, product re-engineering and in-house software development of new technology leading to implementation delays.

Although drones were not fully integrated into the local health system, proof-of-concept was achieved with drones successfully transporting dummy payloads. This project attracted the attention of the Malagasy government, major health service providers and respective funders, who plan to integrate drones into their health provision activities in Madagascar.

\section{THE CASE OF MALAWI}

In the Malawian health sector, two bi-directional drone transport projects are dealing comprehensively with an array of regulatory and operational issues. In 2016, Unicef Malawi, in partnership with VillageReach, implemented a feasibility study on the use of drones to facilitate the transport of dry blood spots for early infant diagnosis of HIV in two rural districts (table 1 and online supplementary file 1). VillageReach conducted an associated costing study in which drone costs were compared with the standard method of transporting samples via motorcycle. ${ }^{14}$ The study found that cost per kilometer is higher for drones compared to motorcycles. However, technology cost is expected to decrease and importantly, cost-effectiveness was not analysed. With support from Unicef, the Malawi Department of Civil Aviation embarked on a process of strengthening regulators' institutional capacity, resulting in the issuance of an Aeronautical Information Circular on drones and draft drone regulations which are currently being finalised by the Ministry of Justice. ${ }^{26}$ In 2018, Unicef commissioned an assessment of the sample referral transportation network and health supply chain in two districts with hard-toreach facilities that modelled the benefits of integrating drones into an optimised specimen referral system. ${ }^{27}$ The study found that the benefits included increased equity and access for patients, responsiveness to urgent needs and potential use in emergencies and catastrophes. Based on these results, the Ministry of Health $(\mathrm{MOH})$ is moving forward with integration of drones in the health system in the two districts. In 2018, VillageReach began conducting a study to assess the acceptability, feasibility, non-inferiority of sample quality, costs and benefits, and possibility of building a business case for the use of drones to transport blood and injectable oxytocin for obstetrical emergencies. ${ }^{22}{ }^{23}$ However, test flights had to be stopped due to GPS interference from cellular towers. Nevertheless, VillageReach and the MOH used the information gained to develop an extensive community mobilisation strategy. ${ }^{23}$ The collaborative efforts of Unicef, VillageReach and other stakeholders in Malawi have addressed initial regulatory, technical, operational and population-based hurdles (figure 1). Remaining technical and operational challenges are being addressed in ongoing projects in collaboration with the $\mathrm{MOH}$. 
Table 1 Characteristics and description of drone projects in Madagascar, Malawi and Senegal

\begin{tabular}{|c|c|c|c|}
\hline & Madagascar & Malawi & Senegal \\
\hline Project name & $\begin{array}{l}\text { DrOTS: Drones Observed } \\
\text { Therapy System in Remote } \\
\text { Madagascar }\end{array}$ & $\begin{array}{l}\text { 1. Specimen referral and health } \\
\text { supply chain optimisation using } \\
\text { drones } \\
\text { 2. Medical commodity delivery for } \\
\text { preventable maternal deaths } \\
\text { using drones }\end{array}$ & $\begin{array}{l}\text { Drones for health supply } \\
\text { payload delivery in } \\
\text { Foundiougne district, Fatick } \\
\text { region, Senegal }\end{array}$ \\
\hline First flight & May 2018 & $\begin{array}{l}\text { 1. } \text { Mar } 2016 \\
\text { 2. Apr } 2018\end{array}$ & $\begin{array}{l}\text { Jan } 2018 \text { (demonstration flights } \\
\text { for regulatory authority) }\end{array}$ \\
\hline Implementer(s) & $\begin{array}{l}\text { Stony Brook University, } \\
\text { Pasteur Institute of } \\
\text { Madagascar }\end{array}$ & $\begin{array}{l}\text { 1. Unicef } \\
\text { 2. VillageReach }\end{array}$ & Ministry of Health, PATH \\
\hline Sponsor(s)/funder(s) & $\begin{array}{l}\text { TB REACH of the Stop TB } \\
\text { Partnership }\end{array}$ & $\begin{array}{l}\text { 1. Unicef (feasibility); Unicef and } \\
\text { USAID (implementation) } \\
\text { 2. Grand Challenges Canada } \\
\text { and Silicon Valley Community } \\
\text { Foundation }\end{array}$ & $\begin{array}{l}\text { The Bill \& Melinda Gates } \\
\text { Foundation }\end{array}$ \\
\hline Drone type(s) & $\begin{array}{l}\text { Hybrid (fixed wing and } \\
\text { quadcopter) }\end{array}$ & $\begin{array}{l}\text { 1. Quadcopter (feasibility); hybrid } \\
\text { (implementation) } \\
\text { 2. Hybrid (fixed wing and } \\
\text { quadcopter) }\end{array}$ & $\begin{array}{l}\text { Hybrid (fixed wing and } \\
\text { quadcopter) }\end{array}$ \\
\hline No of drones & 2 & $\begin{array}{l}\text { 1. To be determined } \\
\text { 2. } 1 \text { in use, } 2 \text { planned }\end{array}$ & To be determined \\
\hline Maximum flight range & $60 \mathrm{~km}$ & $\begin{array}{l}\text { 1. } 100 \mathrm{~km} \\
\text { 2. } 80 \mathrm{~km}\end{array}$ & $60 \mathrm{~km}$ \\
\hline Maximum payload & $1.5 \mathrm{~kg}$ & $\begin{array}{l}\text { 1. } 6 \mathrm{~kg} \text { depending on distance } \\
\text { 2. } 2.2 \mathrm{~kg} \text { (test flight), } 1 \mathrm{~kg} \\
\text { (implementation) }\end{array}$ & $2 \mathrm{~kg}$ \\
\hline Propulsion system & Electric & $\begin{array}{l}\text { 1. Electric } \\
\text { 2. } \text { Electric }\end{array}$ & Electric \\
\hline Flight control & Autonomous but monitored & 1.+2. Autonomous but monitored & Autonomous but monitored \\
\hline Purpose & $\begin{array}{l}\text { Sputum and medication } \\
\text { transport for diagnosis and } \\
\text { treatment of tuberculosis }\end{array}$ & $\begin{array}{l}\text { 1. Collection of medical samples } \\
\text { (TB and HIV diagnosis, viral load) } \\
\text { and delivery of medication } \\
\text { 2. Blood and injectable oxytocin } \\
\text { transport for maternal health } \\
\text { emergencies }\end{array}$ & $\begin{array}{l}\text { Delivery of urgent essential } \\
\text { drugs and collection of medical } \\
\text { samples }\end{array}$ \\
\hline
\end{tabular}


Table 1 Continued

\begin{tabular}{|c|c|c|c|}
\hline & Madagascar & Malawi & Senegal \\
\hline Destination(s) & $\begin{array}{l}\text { A. Peripheral health centre } \\
\text { B. Villages }\end{array}$ & $\begin{array}{l}\text { 1. }+2 \text {. } \\
\text { A. District hospitals } \\
\text { B. Peripheral health centres } \\
\text { C. Blood testing sites }\end{array}$ & $\begin{array}{l}\text { A. District health centre (drone } \\
\text { base) } \\
\text { B. } 3-4 \text { health posts in the dis- } \\
\text { trict (islands) } \\
\text { C. Regional hospital } \\
\text { D. Regional pharmacy }\end{array}$ \\
\hline $\begin{array}{l}\text { Geographical scale, } \\
\text { including health } \\
\text { infrastructure }\end{array}$ & $\begin{array}{l}\text { One district ( } 1 \text { health centre, } 1 \\
\text { health post), including villages }\end{array}$ & $\begin{array}{l}\text { 1. } 2 \text { districts, including islands } \\
\text { 2. } 2 \text { districts (one central blood } \\
\text { bank, } 1 \text { urban health centre, } 1 \\
\text { rural district hospital) }\end{array}$ & $\begin{array}{l}\text { One district, including islands ( } 4 \\
\text { health posts) }\end{array}$ \\
\hline $\begin{array}{l}\text { Total flights (until Dec } \\
\text { 2018) }\end{array}$ & $\begin{array}{l}\text { Six flights (Vayu), } 37 \text { flights } \\
\text { (Vertical Technologies) }\end{array}$ & $\begin{array}{l}\text { 1. } 93 \text { flights } \\
\text { 2. One test flight }\end{array}$ & One test flight \\
\hline $\begin{array}{l}\text { Total deliveries made } \\
\text { (until Dec 2018) }\end{array}$ & $\begin{array}{l}\text { Six round flights (between } \\
10 \text { and } 42 \mathrm{~km} \text { ) using dummy } \\
\text { payloads }\end{array}$ & $\begin{array}{l}\text { 1. None } \\
\text { 2. Not applicable }\end{array}$ & Not applicable \\
\hline $\begin{array}{l}\text { Status of national } \\
\text { regulations }\end{array}$ & $\begin{array}{l}\text { Developed in } 2017 \text {, pending } \\
\text { final approval }\end{array}$ & $\begin{array}{l}\text { Aviation circular developed in } 2017 \text {, } \\
\text { pending final approval }\end{array}$ & Regulations published ${ }^{26}$ \\
\hline
\end{tabular}

\section{THE CASE OF SENEGAL}

In Senegal, since late 2017, the government, in collaboration with PATH, is assessing the usefulness, health impact and cost-effectiveness of drones within the health supply chain system (table 1 and online supplementary file 1 ). The project is being implemented in a region where health facilities are isolated by island geography. Three use cases are being evaluated: (1) transporting laboratory samples for diagnostic tests, (2) delivering treatment for medical emergencies and (3) delivering essential medicines and medical supplies when needed between routine supply trips.

Since the onset, regulatory authorities and governmental stakeholders are engaged, a specific regulatory pathway is defined, an evaluation protocol is drafted, and stakeholders at district level are active participants. Standard operating procedures were established to guide operations, starting from the moment a need for a drone transport is identified until the flight is completed. One main challenge was the overestimation of the technical readiness of the initial drone provider to operate in the given setting. The provider was not able to successfully demonstrate autonomous flights between the base and designated destinations as well as a successful 'return to home' function. Another major challenge was finding freight carriers willing to handle the high-energy-density lithium polymer batteries for shipment to Dakar. The project is currently seeking additional resources to enable another drone provider to receive flight authorisation which will allow operations to begin.

\section{TRACKING AND MEASURING IMPACT}

As with any new intervention, decision-makers and investors need detailed and accurate information about the potential costs and benefits to the health system. To date, no consistent methodology for data collection for drone-based operations has been proposed or employed. Importantly, the implementation of drones might not always translate into immediately identifiable health outcome changes but may be noticeable through surrogate endpoints, such as shorter delays in laboratory sample referrals or a reduction in medical supply stock-outs. ${ }^{28}$ Based on experiences from Madagascar, Malawi and Senegal, we propose a set of standardised indicators to monitor and evaluate the impact of future drone-supported healthcare programmes (table 3 ). This set of qualitative and quantitative indicators should serve as guidance for ongoing or future initiatives and pave the way to a harmonised approach to monitoring the use of bi-directional transport drones for health.

Triangulating data from the five categories presented (ie, health systems performance, process indicators, costs, technical performance and acceptance) 
Table 2 Strengths, weaknesses, opportunities and threats (SWOT) analysis of drone projects in Madagascar, Malawi and Senegal

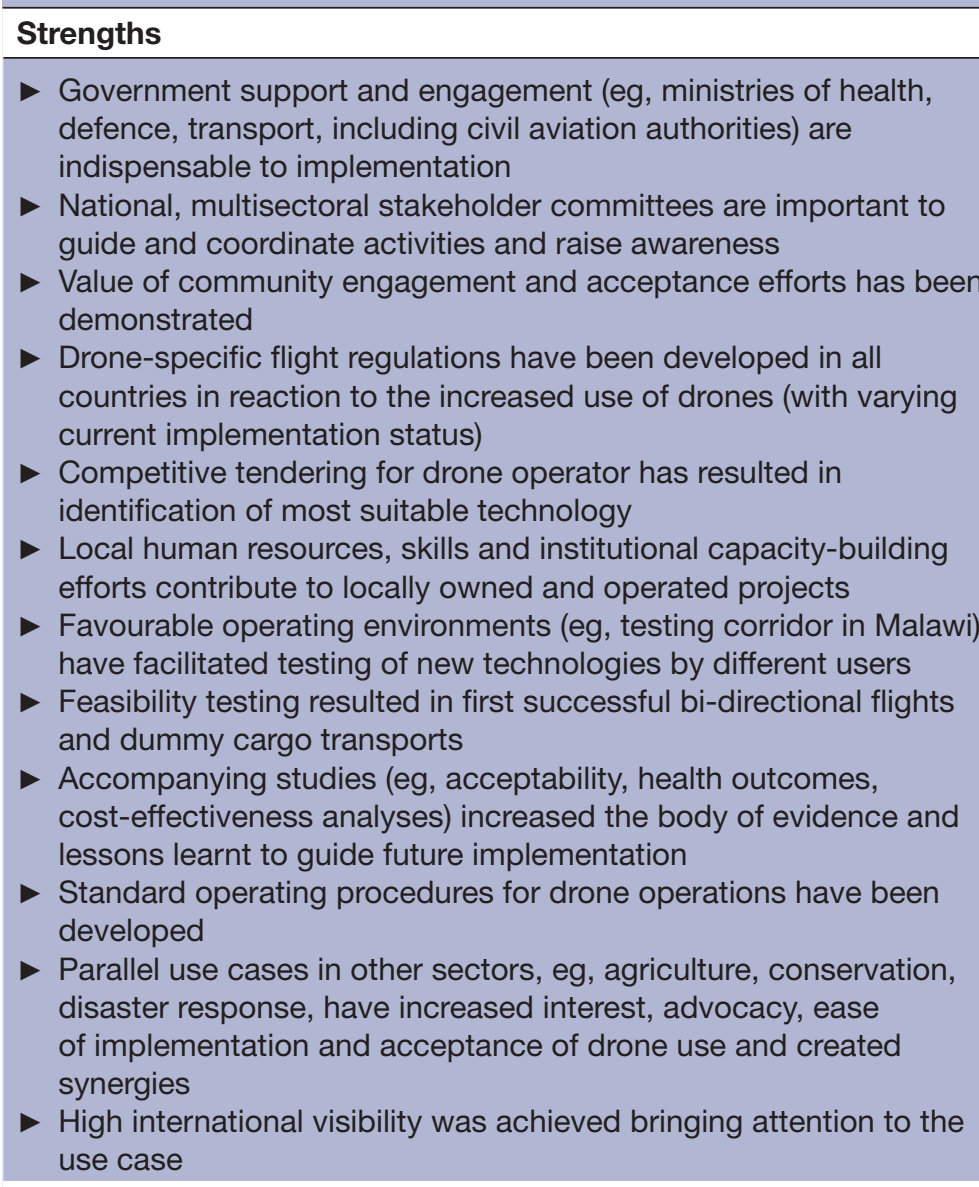

\section{Opportunities}

- Political awareness and desire to work with drones is increasing

- Political interests are aligned with drone project objectives

- Positive feedback from communities on the potential use of drones for health

- African Drone and Data Academy will build local skills and entrepreneurship opportunities

- Supportive regulatory environment enables drone use in absence of final regulations

- Wealth of lessons learnt by the pioneer implementers of bidirectional drone use encourage project continuation and guide new projects

- Drone testing corridor provides opportunities for different types of drones to be tested by different users

- Donor interest to fund existing and new projects

- Potential for cost-effectiveness compared with conventional transport

- Increasing number of use cases reaching more people in need of healthcare

\section{Weaknesses}

- Lengthy and delayed development of drone regulations

- Limited in-country technical capacity

- Lengthy and costly importation of technology and equipment into country

- Need for technology switch mid-projects (technical challenges and unavailability from operating provider)

- Limited readiness of technology in real-world settings (eg, GPS interference) leading to need for technology development on site (software and hardware)

- Difficulty sourcing funding for activities beyond proof-of-concept or small-scale implementation

- Lack of business cases in-country, partly due to lack of implementation beyond proof-of-concept

- Scarcity of data on, eg, performance, impact, acceptability, partly due to recent implementation will allow accurate measurements and evaluation of impacts of drones, including whether the use of drones improved efficiency and equity of service delivery, cost-effectiveness and health outcomes. Measuring these indicators will allow a comparison to (1) baseline before drone implementation and (2) non-drone-supported settings using traditional transportation systems.

\section{Threats}

- Occasional unreliability of currently available technology (hardware and software)

- Limited technical expertise and capacities incountry leading to dependency on external/ international service providers

- Competing interests between in-country health stakeholders

- Sensitivity and potential dangers of delivery of blood or biological samples

- Unsecured funding to continue activities, potentially reversing health gains

- Local health sectors reliant on donor funding with limited ability to assume financial responsibility
Indicators rely on quantitative and qualitative data sources, whereas certain indicators require subjective scales (eg, sample quality), estimations or average values. Since drone-specific data are not recorded in routine health or laboratory information systems, the authors propose the new umbrella term 'drone information system (DIS)' to cover all drone-related flight-log and telemetry data. Integrating certain DIS 


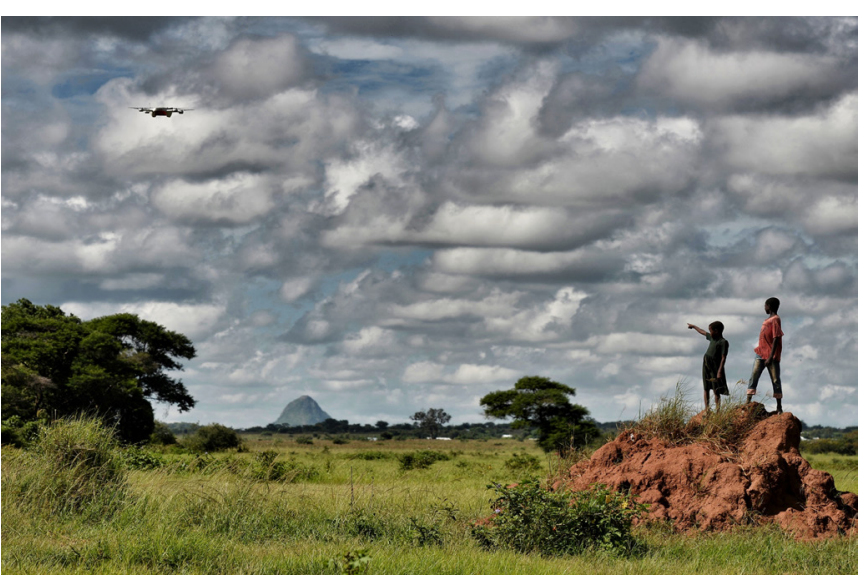

Figure 1 Drone flying in Malawi (March 2016). Messinis/

Matternet.

information within the routine health information system is recommended. For example, 'dispatched and received' logs about payload should be linked to the existing stock registries in health facilities.

\section{RECOMMENDATIONS AND WAYS FORWARD}

This work represents the first collection of hands-on experience on the use of bi-directional transport drones for healthcare in sub-Saharan Africa. Strengths, weaknesses, opportunities and threats across the projects are summarised in table 2. Commonalities and differences in scale, approaches and regulatory landscapes have influenced successes and challenges of each individual drone project. Taken together, they have pioneered the use of bi-directional drones for health purposes on the African continent, provide early experiences for others to build on and encourage the continued use of aerial technology in healthcare provision.

\section{For policy-makers/governments/ministries of health}

For many countries, drone flight regulations were (or still are) new territory and regulatory agencies are faced with the challenge of guaranteeing safety and security of a new technology which may not have had prior commercial applications in-country. ${ }^{29}$ Countries need to develop drone regulations that reflect international guidance (eg, from the International Civil Aviation Organization) and should consider lessons learnt in other countries. For example, Rwanda pioneered the 'performance-based regulations' model, designed to facilitate drone operators' access to airspace through a mission-specific approach. ${ }^{30}$ Therein, regulatory agencies determine the safety requirements for the drone operator's proposed mission, who, in turn, has to prove how it will meet them, no matter the technology used. ${ }^{31}$ This model achieves the balancing act between safety and allowing the use of new technology that would not have been approved if traditional, lengthy certification processes were applied.

Governments should also employ a system-strengthening approach to identify health system bottlenecks and explore new areas for supply chain optimisation and cost-effectiveness using drones. In the planning phase, the use case and technology requirements need to be defined using available tools, including but not restricted to the metrics displayed in table $1 .^{32}$ The suitable technology solution responding to those needs should be provided by manufacturers, which might require new technology development. This process, although longer to start up and costlier initially, is recommended as opposed to relying on readily available but relatively unproven technologies. This approach was recently taken by Unicef Vanuatu and the World Bank Lake Victoria Challenge. ${ }^{33}$

Currently, resources and capacities to mount and maintain a functional drone system are varying across sub-Saharan African countries. The technical base to draw from for fully locally operated drone systems is believed to be sufficient in certain countries. However, there is a limited number of local businesses created for this purpose. In countries where technical resources and human capacities might be limited, an international drone service provider presents a valuable option, at least during an initial phase until local capacity is strengthened. ${ }^{11}$ While drone service providers can be costly and might not always be able to deliver the optimal solution for every setting, they come with technical skills, experience and are bound to deliverables. For sustainable in-country operations and maintenance, local capacity building is a critical factor and should be demanded by governments, facilitated by implementers and supported by funders. To this end, partnerships with local universities and schools of technology offer good opportunities to build local skills and entrepreneurship. For example, WeRobotics' Flying Labs is an international network that works towards localisation of drone solutions through training and business incubation. ${ }^{34}$

Though lead implementing institutions varied across the presented projects-international organisations (Malawi and Senegal) or research institutions (Madagascar)-all were implemented in partnership with the countries' respective health ministries and local governance structures. Government institutions play a paramount role in facilitating project approval, negotiating with regulatory bodies and between ministries, and coordinating a country approach among all health stakeholders even in cases where domestic funding cannot be provided. While implementers might be excited to use innovative technologies, governments are needed to 'steer the drone' so that, with their leadership, drone-supported health systems can really take flight.

\section{For implementers}

After approximately 3 years of implementation of several proof-of-concept drone projects, the technology is still in its feasibility phase for many use cases. To this date, projects have yet to produce sufficient data to demonstrate a direct or indirect impact on health outcomes. We acknowledge that in the context of rapid technology development and short project lifespans, the collection and sharing of performance data has not automatically 

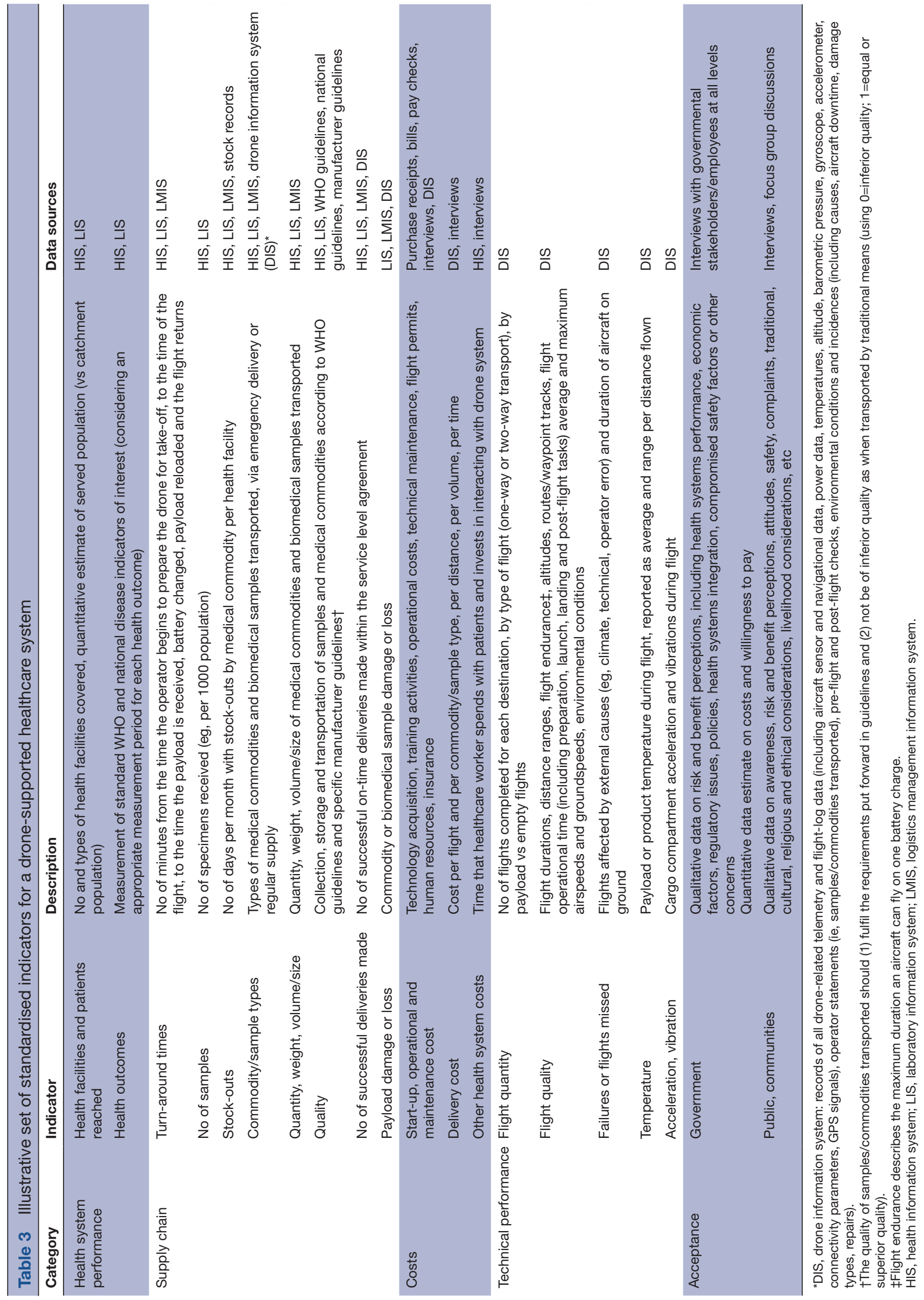
been a priority. However, in light of the increasing country demand for health-related drone projects, it is important that implementers share their data in a timely manner. To properly assess the long-term feasibility and impacts of the use of drones, the indicators listed in table 3 may serve as a minimum guidance for ongoing or future drone projects.

Data will further allow to assess the cost-effectiveness of drone use as compared with a standard of care. A 2016 cost-effectiveness analysis study found that drones can increase vaccine availability and decrease costs as compared with standard of care, if drone use was maximised and optimised to overcome the initial investment and maintenance costs. ${ }^{13}$ However, this is the only modelled cost-effectiveness study currently available whereas real-life data are missing in the public sphere. Importantly, technology costs keep evolving but may be lowered once the technology enters a commercially developed stage. Stakeholders further agree that while cost-effectiveness is an important aspect to consider for countries and funders, cost is not the only or most important factor if lives can be saved. ${ }^{11}$ However, even if shown to be cost-effective, the willingness to pay for drone-supported systems is not guaranteed, especially considering that many countries already lack resources for health supply chain transport needs. ${ }^{35}$

Another important aspect to consider is the local acceptability of the drones, especially when deployed in populations with limited previous exposure to technologies. In Madagascar, an acceptability assessment conducted with community members found a large majority in favour of seeing drone technology being used for healthcare in their community. In Malawi, the acceptability component was assessed through key stakeholder interviews on all levels and focus group discussions in communities. ${ }^{22} 23$ In general, there was low awareness of drones but high acceptability once the idea of drones used for medical transport was introduced. Concerns circled around the safety of people and property, privacy and sustainability, while the main benefit was seen as potential transportation time saved. These studies underline the importance of implementing a comprehensive community mobilisation plan. This ideally includes the physical presentation of a drone (eg, to demystify it, show absence of a camera), comprehensive information on benefits and risks, and operational details (eg, flight paths, flight times, products flown).

In many countries, there will likely be different healthcare providers implementing their own drone projects in the future. While projects can be complementary, with one doing long-distance parachuting and the other short-distance bi-directional transport as an example, there is potential for parallel and competing projects. It is therefore important to coordinate efforts and not burden local health systems with competitive interests. Instead, joint operational or regulatory initiatives might reduce the burden for health ministries and regulatory agencies.

\section{For drone manufacturers and providers}

Three of the projects required changing the initial technology or provider (table 1). Challenges specific to these low-resource countries demonstrated that adjustments to the currently available technology were required. The technology needs to be functional in the most extreme contexts where, for example, the lack of power requires solar-powered systems, the lack of network connectivity needs alternative communication and tracking systems, the lack of technical knowledge needs user-friendly systems, or different weather conditions such as heat requires cargo containers to have integrated cooling systems. So far, bi-directional transport requires technical skills at both ends of the flight. An easy-to-use technology requiring minimal technical knowledge at least on one end (eg, with the community health worker) in combination with minimal but adequate training is needed to make the technology widely applicable. Hence, drone manufacturers and providers are immediately challenged to build robust technologies responding to those real-world needs.

Manufacturers could also scope technology solutions that may exist beyond the public health sphere. Drones used for non-humanitarian purposes might have performance features that humanitarian drones still lack and which could support the advances needed for the public health field.

Based on our experience, several weeks are required initially for drone providers to be in-country to test and adjust technologies. The context-specific challenges faced by implementers operating in different countries, such as importation of equipment or cell phone tower interference issues, confirm the importance of allowing ample time for testing.

Since other transport conditions are unlikely to change rapidly in remote areas in sub-Saharan Africa, reliable drone technology makes a compelling business model if local needs can be met. This holds true for drone technology, repair parts and other associated equipment. For example, the shipment and importation of lithium polymer batteries posed a challenge in Madagascar and Senegal. The upsurge in private and commercial drone use presents a local business opportunity for importation of batteries and other drone parts, as well as recycling of some of these components for other purposes (eg, re-using drone batteries in solar energy systems).

\section{For sponsors/funders}

The projects presented here were all fully supported by foreign funding, although importantly, local ministries contributed through provision of structures and personnel. Implementers of the projects presented here have been approached by major donors such as the Global Fund to Fight AIDS, Tuberculosis and Malaria, the Bill \& Melinda Gates Foundation, and USAID enquiring about experiences and potential evidence. For developers, implementers and researchers alike, it would be helpful if funders were explicit about what evidence they need 
(eg, cost-effectiveness, safety, acceptability, local sustainability) before deciding to fund.

At this stage, funders need to be aware that they invest in a technology still needing iterative development in realworld contexts. Ample flexibility in funding is needed so that implementers can keep up with the rapid pace at which the technology is changing. In addition, comparable with the phases of drug development trials, drone software and hardware development, impact evaluation and final implementation requires longer-term investment, with funds that go beyond pilot projects. The field may also seek investment from the private sector, investment funds or venture capital sources in order to more quickly reach the point of technical robustness needed.

\section{CONCLUSION}

We conclude that drones are increasingly being tested for healthcare purposes around the globe. They can be understood as a tool complementary to existing transport systems offering advantages over traditional approaches in certain circumstances. How and where drones optimally fit into health systems is still being determined and will depend on local needs and resources. Currently, projects attempting bi-directional drone transport are still exploring the possibilities, advancing the technologies and gathering real-world experiences.

The integration and optimisation of new technologies into health systems is a process over several years. As a recent example, mobile health (m-Health) solutions experienced a slow start in the 1990s. ${ }^{36}$ Its use increased rapidly in the wake of computer and communication networks and more recently smartphones, surpassing geographical, temporal and organisational barriers. In evolving technological and market environments, drones could take a similar trajectory. As with any innovative health intervention, the sustainability of drone-supported healthcare systems will further necessitate strong capacity building, an efficient impact monitoring and evaluation cycle and in-country commitment, including investment in drone regulations, project design and long-term ownership.

Our projects presented here were able to overcome challenges and demonstrate successes with regards to regulations, in-country collaborations, proof of feasibility, information sharing and local acceptability. Based on the experiences gained to date, drones are worth future investments given their compelling prospect to support universal health coverage in sub-Saharan Africa and beyond.

\author{
Author affiliations \\ ${ }^{1}$ Mycobacteria Unit, Institut Pasteur de Madagascar, Antananarivo, Madagascar \\ ${ }^{2}$ Swiss Tropical and Public Health Institute, Basel, Switzerland \\ ${ }^{3}$ Global Health Institute, Stony Brook University, Stony Brook, New York, USA \\ ${ }^{4}$ UNICEF Supply Division, Supply Chain Strengthening Centre, Interagency Supply \\ Chain Group, Copenhagen, Denmark \\ ${ }^{5}$ UNICEF Malawi, Lilongwe, Malawi \\ ${ }^{6}$ VillageReach Malawi, Lilongwe, Malawi \\ ${ }^{7}$ VillageReach Seattle, Seattle, Washington, USA
}

${ }^{8}$ PATH Senegal, Dakar, Senegal

${ }^{9}$ PATH, Seattle, Washington, USA

${ }^{10}$ UNICEF Madagascar, Antananarvio, Madagascar

${ }^{11}$ Centre de Recherche du Centre Hospitalier de l'Université de Montréal, Montréal, Quebec, Canada

Acknowledgements We thank governmental and other stakeholders in all countries for their continued collaboration on the herein presented drone projects. We particularly thank all teams and individuals who have worked towards the successes of these projects. We are grateful to the populations affected by the drone projects in the respective countries for accepting and allowing our teams to work in their communities and dedicating their time for the purpose of research. Special thanks to Thokozani Chimenya (VillageReach, Malawi) for analysis of focus group discussions held in Malawi and Samuel Weiss (Purpose Built Drones, USA) for critical review of the paper.

Contributors AMK, SGL and SdIR conceptualised the manuscript. AK wrote the first draft of the manuscript. SdIR, JS, CB, CM, LM, ODD, AG, JR, JM, JB, NR, PS and SGL all contributed to the manuscript content. All authors provided iterative feedback on the manuscript and approved its final version. AMK and SGL are guarantors of the final manuscript.

Funding The DrOTS project in Madagascar was funded by the Stop TB Partnership's TB REACH initiative supported by Global Affairs Canada. Unicef's activities in Malawi were supported by UNICEF core resources. The VillageReach blood and oxytocin study was funded by Grand Challenges Canada and Silicon Valley Community Foundation. PATH's work in Senegal was funded by a grant from the Bill \& Melinda Gates Foundation. AMK is supported by the Rudolf Geigy Foundation, Swiss Tropical and Public Health Institute, Basel, Switzerland. SGL is supported by the Canadian Association for Microbiology and Infectious Diseases.

Disclaimer The views expressed herein are solely those of the authors and do not necessarily reflect the views of the organisations/agencies they work for.

Competing interests None declared.

Patient consent for publication Not required.

Provenance and peer review Not commissioned; externally peer reviewed.

Data availability statement № additional data are available.

Open access This is an open access article distributed in accordance with the Creative Commons Attribution Non Commercial (CC BY-NC 4.0) license, which permits others to distribute, remix, adapt, build upon this work non-commercially, and license their derivative works on different terms, provided the original work is properly cited, appropriate credit is given, any changes made indicated, and the use is non-commercial. See: http://creativecommons.org/licenses/by-nc/4.0/.

\section{REFERENCES}

1. WHO. Everybody's business: strengthening health systems to improve health outcomes: WHO's framework for action. Geneva: World Health Organization, 2007.

2. Fornace KM, Drakeley CJ, William T, et al. Mapping infectious disease landscapes: unmanned aerial vehicles and epidemiology. Trends Parasitol 2014;30:514-9.

3. Mark DB, Hansen SM, Starks ML, et al. Drone-based automatic external defibrillators for sudden death? Do we need more courage or more serenity? Circulation 2017;135:2466-9.

4. Time USA. Startup Zipline has teamed up with the Rwandan government to deliver blood supplies by drone, 2017. Available: http://time.com/rwanda-drones-zipline/

5. USAID. Unmanned aerial vehicles landscape analysis: applications in the development context. Washington DC: USAID Global Health Supply Chain Program-Procurement and Supply Management, 2017.

6. Guillen-Perez A, Cano MD. Flying ad hoc networks: a new domain for network communications. Sensors 2018;18:3571-823.

7. Karaca Y, Cicek M, Tatli O, et al. The potential use of unmanned aircraft systems (drones) in mountain search and rescue operations. Am J Emerg Med 2018;36:583-8.

8. UN. Mosquito-packed drones ready to join fight against Zika and other deadly diseases New York: UN news, 2018. Available: https:// news.un.org/en/story/2018/04/1007672

9. McCall B. Sub-Saharan Africa leads the way in medical drones. The Lancet 2019;393:17-18.

10. MSF. Innovating to reach remote TB patients and improve access to treatment: Médecins Sans Frontières, 2014. Available: https://www. 
msf.org/papua-new-guinea-innovating-reach-remote-tb-patientsand-improve-access-treatment

11. Dirks W. Evaluation of the business case for cargo drones in humanitarian action: qualitative analysis. Tokyo: Médecins Sans Frontières (MSF), 2017.

12. The Lancet Haematology. Look! Up in the sky! It's a bird. It's a plane. It's a medical drone! Lancet Haematol 2017:4:e56.

13. Haidari LA, Brown ST, Ferguson M, et al. The economic and operational value of using drones to transport vaccines. Vaccine 2016;34:4062-7.

14. Phillips N, Blauvelt C, Ziba M, et al. Costs associated with the use of unmanned aerial vehicles for transportation of laboratory samples in Malawi. Seattle: VillageReach, 2016.

15. USAID. Center for Accelerating Innovation and Impact. UAVs in global health-defining a collective path forward. Washington DC: U.S. Agency for International Development, 2017.

16. Scott JE, Scott CH. Drone delivery models for healthcare. Waikoloa: Proceedings of the 50th Hawaii International Conference on System Sciences, 2017.

17. ANSI. Standardization roadmap for unmanned aircraft systems, Version 1.0. Washington DC: ANSI Unmanned Aircraft Systems Standardization Collaborative (UASSC), 2018.

18. Amukele TK, Street J, Carroll K, et al. Drone transport of microbes in blood and sputum laboratory specimens. J Clin Microbiol 2016;54:2622-5.

19. Eichleay MM, Murashani S, Mercer S. Using unmanned aerial vehicles for development: perspectives from citizens and governments officials in Tanzania. Durnham: FHI360, 2016.

20. Priye $\mathrm{A}$, Wong $\mathrm{S}, \mathrm{Bi}$ Y, et al. Lab-on-a-drone: toward pinpoint deployment of smartphone-enabled nucleic acid-based diagnostics for mobile health care. Anal Chem 2016;88:4651-60.

21. Amukele TK, Hernandez J, Snozek CLH, et al. Drone transport of chemistry and hematology samples over long distances. Am J Clin Pathol 2017:148:427-35.

22. Matemba C, Maxim L, Chimenya T. Stakeholder awareness and perception assessment as a prerequisite in designing informed community-based communication strategies for remotely piloted aircrafts (RPA) flight tests: focus groups findings from Lilongwe and Dowa districts. Malawi National Conference on Communication for Development, Lilongwe, 2018.

23. Matemba C, Maxim L, Chimenya T. Stakeholder and community engagement are critical to the deployment of unmanned aerial vehicles (UAVs) for public health transport: a case study from Malawi. Lusaka: Global health supply chain summit, 2018.

24. Nouvet E, Knoblauch AM, Passe I, et al. Perceptions of drones, digital adherence monitoring technologies and educational videos for tuberculosis control in remote Madagascar: a mixed-method study protocol. BMJ Open 2019;9:e028073.

25. ABC News. Doctors use drones to drop medical supplies in Madagascar New York: ABC news internet ventures, 2017. Available: https://abcnews.go.com/Nightline/video/doctors-drones-dropmedical-supplies-madagascar-46880863

26. ANACIM. Annexe 5 Au règlement aéronautique du Sénégal $N^{\circ} 06$ : systèmes d'aéronefs telepilotes. Dakar: Agence Nationale de l'Aviation Civile et de la Météorologie, 2018.

27. John Snow Inc. Network assessment \& system design for transportation of EID samples and test results in Malawi. Arlington, 2018.

28. Pai M, Schumacher SG, Abimbola S. Surrogate endpoints in global health research: still searching for killer apps and silver bullets? BMJ Glob Health 2018;3:e000755.

29. Global drone regulations database: UAViators, FSD, technical centre for agricultural and rural cooperation, OZYRPAS consulting, 2018. Available: https://droneregulations.info

30. WEF. Advanced drone operations toolkit: accelerating the drone revolution. Geneva: World Economic Forum, 2019.

31. Russo A, Wolf $\mathrm{H}$. What the world can learn from Rwanda's approach to drones. Geneva: World Economic Forum, 2019. Available: https:// www.weforum.org/agenda/2019/01/what-the-world-can-learn-fromrwandas-approach-to-drones/

32. Eichleay M, Evens E, Parker C, et al. UAV delivery decision tool, 2019. Available: https://fhi360.shinyapps.io/UAVDeliveryDecis ionTool/

33. Ministry of Health Vanuatu. Request for tender: physical services: transportation of vaccines and medical supplies using unmanned aircraft systems (UAS) or drones. Port Vila: Ministry of Health Vanuatu, 2018.

34. WeRobotics. Flying Labs. Geneva: WeRobotics, 2019. Available: https://werobotics.org/flying-labs/

35. Yadav P. Health product supply chains in developing countries: diagnosis of the root causes of underperformance and an agenda for reform. Health Systems \& Reform 2015;1:142-54.

36. Silva BMC, Rodrigues JJPC, de la Torre Díez I, et al. Mobile-health: a review of current state in 2015. J Biomed Inform 2015;56:265-72. 